MESOSCALE MODELING OF

DEFLAGRATION-INDUCED

DECONSOLIDATION IN

POLYMER-BONDED EXPLOSIVES

H. K. Springer, E. A. Glascoe, J. E. Reaugh, J. R. Kercher, J. L. Maienschein

August 4, 2011

17th APS SCCM Conference Chicago, IL, United States June 26, 2011 through July 1, 2011 
This document was prepared as an account of work sponsored by an agency of the United States government. Neither the United States government nor Lawrence Livermore National Security, LLC, nor any of their employees makes any warranty, expressed or implied, or assumes any legal liability or responsibility for the accuracy, completeness, or usefulness of any information, apparatus, product, or process disclosed, or represents that its use would not infringe privately owned rights. Reference herein to any specific commercial product, process, or service by trade name, trademark, manufacturer, or otherwise does not necessarily constitute or imply its endorsement, recommendation, or favoring by the United States government or Lawrence Livermore National Security, LLC. The views and opinions of authors expressed herein do not necessarily state or reflect those of the United States government or Lawrence Livermore National Security, LLC, and shall not be used for advertising or product endorsement purposes. 


\title{
MESOSCALE MODELING OF DEFLAGRATION-INDUCED DECONSOLIDATION IN POLYMER-BONDED EXPLOSIVES
}

\author{
H. K. Springer, E. A. Glascoe, J. E. Reaugh, J. R. Kercher, and J. L. Maienschein \\ Lawrence Livermore National Laboratory, Livermore, CA. 94551
}

\begin{abstract}
Initially undamaged polymer-bonded explosives can transition from conductive burning to more violent convective burning via rapid deconsolidation at higher pressures. The pressure-dependent infiltration of cracks and pores, i.e., damage, by product gases at the burn-front is a key step in the transition to convective burning. However, the relative influence of pre-existing damage and the evolution of deflagration-induced damage during the transition to convective burning is not well understood. The objective of this study is to investigate the role of microstructure and initial pressurization on deconsolidation. We performed simulations using the multi-physics hydrocode, ALE3D. HMX-Viton A served as our model explosive. A Prout-Tompkins chemical kinetic model, Vielle's Law pressure-dependent burning, Gruneisen equation-of-state, and simplified strength model were used for the HMX. The propensity for deconsolidation increased with increasing defect size and decreasing initial pressurization, as measured by the increase in burning surface area. These studies are important because they enable the development of continuum-scale damage models and the design of inherently safer explosives.
\end{abstract}

Keywords: Deflagration-induced damage, deconsolidation, convective burning, mesoscale, ALE3D. PACS: $62.20 . \mathrm{mm}, 82.33 . \mathrm{Vx}$

\section{INTRODUCTION}

Accurate predictions of explosive violence in hazard scenarios require a detailed understanding of its state of damage during the deflagration process. While previous studies have focused on deflagration subsequent to direct mechanical insults [1] or thermal insults [2-6], the objective of this study is to investigate the material deconsolidation due to the deflagration itself. Evidence of deflagration-induced deconsolidation in some HMX-based formulations has been observed in high pressure strand burner and other closed bomb experiments $[2,4,6,7]$. The propensity for such deconsolidative behavior in polymerbonded explosives has been shown to increase with increasing volume fraction of explosive, increasing brittleness of binder or overall explosive, and at relatively higher pressures [7-9]. A key mechanism implicated in deconsolidative burning is the pressure-dependent infiltration of small, surface grain defects or grain-binder interface defects by the flame front. Flame penetration is enabled by the decrease in flame standoff (distance) at higher pressures. But increasing the initial pressure can also close defects in the explosive. So a competition exists between flame-infiltration of surface defects and closure of these defects by pressurization of the explosive. Mesoscale simulations can provide insights into these competing mechanisms underlying deflagrationinduced deconsolidation. In this study, we investigated the influence of defects, initial pressurization, and length-scale on the deconsolidative burning of a HMX-Viton explosive formulation. 
TABLE 1. Strength and equation-of-state parameters for HMX reactant (top ) [12,13,16], Viton A (bottom) [14-15]

\begin{tabular}{|c|c|c|c|c|c|c|c|c|}
\hline $\begin{array}{c}\rho_{0} \\
\mathrm{~g} / \mathrm{cc}\end{array}$ & $\begin{array}{c}\mu \\
\text { Mbar }\end{array}$ & $\begin{array}{c}Y_{0} \\
\text { Mbar }\end{array}$ & $\begin{array}{c}\rho_{0} C_{v} \\
\operatorname{Mbar} / \mathbf{K}\end{array}$ & $\begin{array}{c}k \\
\operatorname{Mbar}^{-c^{2}} / \mathrm{K}-\mu \mathrm{s}\end{array}$ & $\begin{array}{c}\mathrm{c} \\
\mathrm{cm} / \mu \mathrm{s}\end{array}$ & $S_{1}$ & $\mathbf{S}_{2}$ & $\gamma_{0}$ \\
\hline 1.903 & $7.00 \mathrm{E}-2$ & $1.80 \mathrm{E}-3$ & $2.40-5$ & $3.80 \mathrm{E}-14$ & $2.74 \mathrm{E}-1$ & 2.60 & 0.0 & 1.10 \\
\hline 1.865 & $2.04 \mathrm{E}-5$ & $1.07 \mathrm{E}-4$ & $1.46 \mathrm{E}-5$ & $2.26 \mathrm{E}-14$ & $1.71 \mathrm{E}-1$ & 1.92 & $-1.58 \mathrm{E}-1$ & -- \\
\hline
\end{tabular}

\section{MODEL DESCRIPTION}

We performed mesoscale simulations of deflagration-induced deconsolidation in 2D planestrain mode with LLNL's multi-physics, arbitrarylagrangian-eulerian code, ALE3D [10]. Single HMX grain simulations have a material domain size of $100 \mu \mathrm{m}$ by $100 \mu \mathrm{m}$. Defects (rectangular voids) of varying length were introduced to all single grain simulations. Multiple HMX grain simulations have a material domain size of 1000 $\mu \mathrm{m}$ by $1000 \mu \mathrm{m}$. The binder layer (half-thickness) in both single and multiple HMX grain simulations was set to $3.5 \mu \mathrm{m}$, which is representative of LX07 (90\%wt. HMX, 10\%wt. Viton A). Voronoi tessellation techniques were used to initiate the microstructure in multiple HMX grain simulations [11].

\section{Material Properties}

For these calculations, straightforward mechanical-thermal-chemical models were used for HMX grains. We assumed individual grains to have isotropic (bulk) properties rather than anisotropic material properties based on crystalline directions.

\section{Thermomechanical Properties}

A constant strength model, in conjunction with Von Mises yield criteria, and a Gruneisen equation-of-state model was used for the HMX reactant and the Viton A binder. The Gruneisen equation-of-state model is shown in eq. (1),

$$
P=\frac{\rho_{0} c^{2} \mu\left[1+\left(1+\frac{\gamma_{0}}{2}\right) \mu-\frac{a \mu^{2}}{2}\right]}{\left[1-\left(S_{1}-1\right) \mu-S_{2}\left(\frac{\mu^{2}}{\mu+1}\right)\right]^{2}}+\left(\gamma_{0}+a \mu\right) e
$$

where $P$ is the pressure, $\rho_{0}$ is the initial density, $c$ is the intercept of the $U_{s^{-}} U_{p}$ curve, $S_{1}$ and $S_{2}$ are the coefficients of the slope of the $U s-U p$ curve, $\gamma_{0}$ is the Gruneisen gamma, $a$ is the first order correction to $\gamma_{0}, e$ is the energy per unit volume, and $\mu$ is a function of compression related to density $\left(\mu=\rho / \rho_{0}\right.$ - 1). Parameters for the strength, equation-of-state, heat capacity, and conductivity are shown in Table 1. Room temperature thermal transport properties are given in Table 1 [16]. HMX product gas equation-of-state and thermal transport properties were taken from literature $[16,17]$.

\section{Chemical Properties}

The extended Prout-Tompkins nucleation and growth global kinetic model was selected for HMX decomposition. Further details, including HMX model parameters, can be found in Wemhoff et al. [18]. model is shown in eq. (2),

$$
\frac{d x}{d t}=\left(A^{-E / R T}\right)(1-x)^{n}(1-q(1-x))^{m}
$$

where $x$ is the fraction reacted, $E$ is the activation energy, $R$ is the gas constant, $T$ is the temperature, $A$ is the prefactor, and $n, m$, and $q$ are unitless variables associated with the reaction order, autocatalysis, and nucleation, respectively. The parameters for the extended Prout-Tompkins model are shown in Table 2.

TABLE 2. Prout-Tompkins chemical kinetic parameters for HMX [18]

\begin{tabular}{ccccc}
\hline $\boldsymbol{E}$ & $\boldsymbol{\operatorname { l n } ( \boldsymbol { A } )}$ & $\mathbf{n}$ & $\mathbf{m}$ & $\mathbf{q}$ \\
& $\log (\mathbf{1} / \boldsymbol{\mu s})$ & & & \\
\hline $7.59 \mathrm{E}+4$ & 59.86 & 0.34 & 1.26 & 0.99 \\
\hline
\end{tabular}


A level-set method described elsewhere [19] was employed to evolve (numerical) element-scale burning according to Vielle's Law for conductive burning $\left(=\mathrm{Ap}^{\mathrm{v}}\right)$. The prefactor $(A)$ is $2.8 \mathrm{~mm} / \mathrm{s}$, the exponent $(v)$ is 0.97 , and the pressure $(p)$ is in $\mathrm{MPa}$ [20]. A thermal boundary condition was used to initiate this burning in the HMX grains. Viton A was treated as an inert material with no inherent chemical reactivity.

\section{RESULTS AND DISCUSSION}

Figure 1 shows the progression of a typical single HMX grain simulation. In general, we observe that the HMX product gases infiltrate the binder interface (defect) faster than the grain defect. Faster infiltration can be attributed to the lower yield strength in the Viton A binder relative to the HMX grain. After engulfing the grain in hot product gas, burning is initiated over the entire outer periphery and proceeds inwards. This tends to increase the effective surface area for burning.
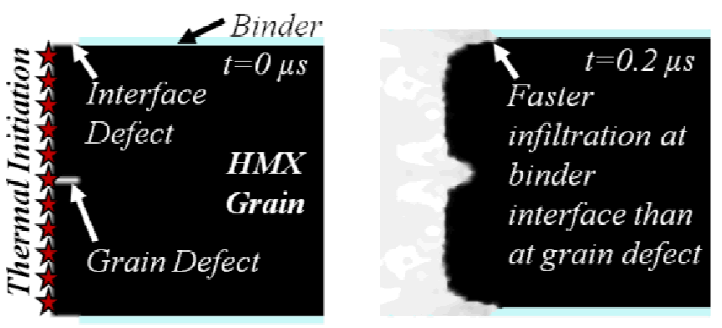

FigUrE 1. Spatial density plots from single-grain HMX simulation. 1a) At $\mathrm{t}=0 \mu \mathrm{s}$, the material domain consists of a single HMX grain (black) and binder (blue). Thermal initiation occurs at the left-most material boundary. Defects lengths of 1,10 , and $25 \mu \mathrm{m}$ were introduced into the HMX grain and at the binder interface. 1b) At $t=0.2 \mu \mathrm{s}$, the product gases are shown to infiltrate the defect in binder interface faster than the defect in the grain.

Defect lengths of 1,10 , and $25 \mu \mathrm{m}$ were introduced into the HMX grain and at the grainbinder interface. In each case, the initial pressure was set to $100 \mathrm{MPa}$. Longer defects resulted in faster consumption of HMX and a higher effective surface area ratio $\left(\mathrm{S} / \mathrm{S}_{0}\right)$ (see Figure 2$) . \mathrm{S} / \mathrm{S}_{0}$ is the ratio of predicted mass fraction reacted (for each simulation) to mass fraction reacted for conductive burning. The conductive burning mass fraction reacted is calculated using the initial pressure in each simulation (100 MPa in these studies). With larger defects, product gases encounter less resistance during infiltration at binder interface and more rapidly initiate and burn the explosive grains.

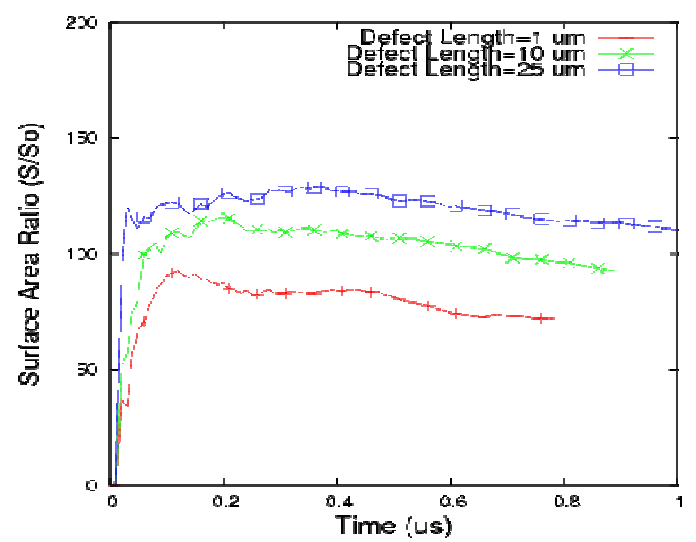

Figure 2. Surface area ratio $\left(S / S_{0}\right)$ for defect lengths of 1,10 , and $25 \mu \mathrm{m}$.

Surprisingly, increasing the initial pressure from 100 to $250 \mathrm{MPa}$ depresses the rate of HMX consumption and reduces $\mathrm{S} / \mathrm{S}_{0}$ (see Figure 3 ). In each case, the initial defect size is $10 \mu \mathrm{m}$. This result is counterintuitive because the burn rate increases at higher initial pressures. However, the rate of gas infiltration into the grain-binder interface is reduced at higher initial pressures, as well, leading to a reduced burning area.

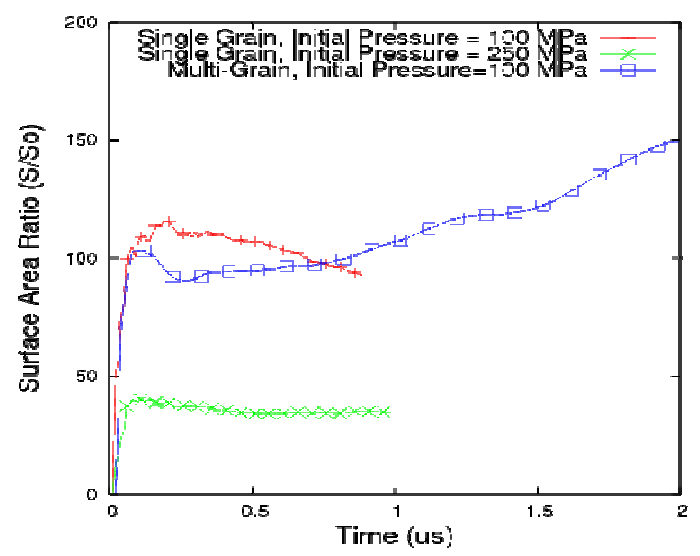

FigURE 3. Surface area ratio $\left(\mathrm{S} / \mathrm{S}_{0}\right)$ for single grain cases (100 and $250 \mathrm{MPa}$ ) and multi-grain cases (100 MPa). 
Figure 4 shows the progression of a multigrain HMX simulation. In these simulations we observe that the hot product gas infiltrates the grain-binder interface, progressively debonding entire HMX grains and initiating burning over their outer periphery. As shown in Figure $3, \mathrm{~S} / \mathrm{S}_{0}$ predictions for the multi-grain and single grain cases at $100 \mathrm{MPa}$ are within $30 \%$ of each other up to approximately $0.75 \mu \mathrm{s}$. However, beyond 0.25 $\mu \mathrm{s}, \mathrm{S} / \mathrm{S}_{0}$ tends only to increase for the multi-grain cases. This later time effect can be explained by the relatively higher density of grain boundaries, i.e., potential surface area for burning, in the multigrain case than in the single grain case. Grain boundaries, in turn, are related to the grain size distribution. Recalling that $\mathrm{S} / \mathrm{S}_{0}$ is based on reacted mass fraction, where the mass reacted is normalized by total energetic mass (reacted and unreacted), the multi-grain will certainly have a higher density of grain boundaries for a given amount of HE. This is also qualitatively evident by comparing the binder content to Figures 1 and 4.
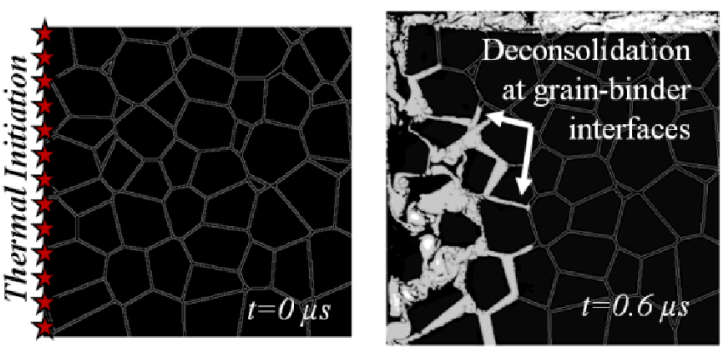

FigUre 4. Spatial density plots from multi-grain HMX simulation showing deconsolidation during burning. 4a) At $\mathrm{t}=0 \mu \mathrm{s}$, the material domain $(1000 \mu \mathrm{m}$ by $1000 \mu \mathrm{m})$ consists of HMX grains (black) and binder interfaces (white). Thermal initiation occurs at the left-most material boundary. $4 \mathrm{~b}$ ) At $\mathrm{t}=0.6 \mu \mathrm{s}$, deconsolidation is shown to occur at grain-binder interfaces.

\section{CONCLUSIONS}

Multi-physics, mesoscale simulations were performed to investigate deflagration-induced deconsolidation of a HMX-Viton explosive formulation. Single HMX grain simulations show that defects at the grain-binder interface are more important to hot product gas infiltration than internal grain defects, $S / S_{0}$ increases with defect size, and smaller initial pressures does not impede grain-binder interface infiltration by hot product gases, allowing more enhancement of burning surface area. Multi-grain simulations show further increases to $\mathrm{S} / \mathrm{S}_{0}$, possibly due to the larger density of grain boundaries, i.e., potential sites for burning.

\section{ACKNOWLEDGEMENTS}

This work was performed under the auspices of the U.S. DOE by LLNL under Contract DEAC52-07NA27344. This research was supported by the Joint DoD-DOE Munitions Technology Development Program.

\section{REFERENCES}

1. Maienschein, J. L., et al., LLNL Report, UCRL-ID130077, 1998.

2. Maienschein, J. L., et al, in Proc. $11^{\text {th }}$ Int. Det. Symp., p. 872, 1998.

3. Wardell, J. F. and Maienschein, J. L., in Proc. $12^{\text {th }}$ Int. Det. Symp., p. 384, 2002.

4. Maienschein, J. L., et al., Propellants, Explosives, Pyrotechnics, 29:5, p.287, 2004.

5. Glascoe, E. A., et al., submitted to SCCM, 2011

6. Koerner, J., et al., in Proc. $13^{\text {th }}$ Int. Det. Symp., p. 527, 2006.

7. Fifer, R. A., et al., in Proc. $7^{\text {th }}$ Int. Det. Symp., p. 164, 1981

8. Asay, B. W., et al., Int. J. Multiphase Flow, 22:5, p.923, 1996.

9. Asay, B. W. (ed.), Shock Wave Science \& Technology Library Vol. 5: Non-Shock Initiation of Explosives, Springer-Verlag, p. 293, 2010.

10. Nichols, A. L., LLNL Report, UCRL-MA-152204, 2007.

11. Friedman, G., LLNL Report, LLNL-SM-458031, 2011.

12. Menikoff, R., et al., J. Appl. Phys., 97, 023529, 2005.

13. Olinger, B., et al., in Proc. Symp. (Int.) on High Dynamic Pressures, Paris, France, p. 3, 1979.

14. Dupont Technical Literature on Viton A, 2011.

15. Baer, M. R., private communication, 2010.

16. Tarver, C. M. and Tran, T. D., Combustion and Flame, 137, p.50, 2004.

17. Dobratz, B., LLNL Report, UCRL-52997 Change 2

18. Wemhoff, A. P., et al., J. Phys. Chem. A, 112, 9005, 2008.

19. Yoh, J. J., et al., J. Appl. Phys., 97, 083504, 2005.

20. Esposito, A. P., et al., Propellants, Explosives, Pyrotechnics, 28:2, p.83, 2003. 